\title{
Digitalisation in Agriculture: Roads Ahead
}

\author{
Snehika Pandia*, Reeba Sharma, Nandani Shukla and Roopali Sharma \\ Department of Plant Pathology, Govind Ballabh Pant University of Agriculture and \\ Technology, Pantnagar, Uttarakhand-263145, India \\ *Corresponding author
}

\section{Keywords}

Digitalisation, Information and Communication

Technology, Digital Earth

Article Info

Accepted:

15 November 2019

Available Online:

10 December 2019

\section{A B S T R A C T}

Agriculture is the back bone of India and a majority of Indians depend on agriculture for their livelihood. Major challenges confronting Indian agriculture include declining total productivity, diminishing and degrading natural resources, a rapidly growing demand for food, stagnating farm incomes, fragmented land holdings and unprecedented climate change. Indian farmers are not getting expected income from agriculture due to many problems relating to pest and disease, pesticides, fertilizer, processing etc. Technology adoption modernizes farmers' production practices and leads to uniform annual returns for farmers, reduced risk of crop failure, and increased yields. Like the concept of 'Digital Earth', digitalization in agriculture is the combination of ICT and data ecosystems to support the agricultural development. This paper is an attempt to get an insight into the problems faced by the farmers, the concept of digitalisation and the ways in which digitalization process is helping them to overcome the same.

\section{Introduction}

In order to transform the entire ecosystem of public services through the use of information technology, the Government of India has launched the Digital India program on 1 July 2015 with the vision to transform India into a digitally empowered society and knowledge economy. The agricultural sector that employs 50 per cent of the country's population claims a huge impact on the overall growth of the country. So, there is a growing opportunity for the use of digital technology in agricultural sector that stands to improve lives, make India a true leader in Climate-smart agriculture and revolutionize the way farmers plant, fertilize and harvest crops. This sector can reap the benefits from the Technology driven solutions to improve supply chain and farming practices, which together can have the impact of improved yield and higher monetization for the sector (Verma, 2017). 
Important challenges of Indian Agriculture sector

The agriculture sector challenges will be important to India's overall development and the improved welfare of its rural poor. The challenges are as stated below:

By 2050 the world will have additional 2 billion and India has to feed 750 million.

India is currently using resources $50 \%$ faster than world can sustain.

Every second, India loses a football field size of farm land due to soil erosion and urbanisation.

India has total 329 million hectares of land of which round 37\% (120.40 million hectare) of the country's total geographical area is affected by various kinds of land degradation.

On an average 16.4 tonnes of fertile soil is lost every year per hectare.

India's small-holder farmers (those owning less than 2.0 hectares of farmland) comprise 78 percent of the country's farmers, but own only 33 percent of the total cultivated land; they nonetheless produce 41 percent of the country's food-grains.

Current farming technology costs far more than most farmers can afford.

While a food scarcity may sound like a faraway problem right now, it's a reality that India could be facing in as little as 15 years. India's growth has been largely jobless, with only 15 million jobs created during the last 10 years. With employment per factory declining steeply over the years, the chances for a revival seem difficult. Hence, policy makers have to initiate and include policy actions and public programs to develop this sector and make it much more productive, internationally competitive, and diversified agricultural sector (Shalini and Biswas, 2016)

\section{Digitalization in agriculture}

The convergence of agriculture and information and communication technology (ICT) is a new development in India which is intended to increase efficiency in every process of production, distribution and consumption. This system can be also described as an integrated agricultural system. The main keys of the integrated agricultural system includes data processing and digital control machinery for digitization, data transmission, data collection, network and automation of agricultural activity (Tang, 2002). The current agriculture has converged with technologies such as information technology (IT), biotechnology (BT), environment technology (ET), and nanotechnology (NT) and it mainly focuses on areas such as cost reduction during production level, reduction in labor burden, high quality and organic production, and quality management in facility. Second, it is important to meet consumers' needs at the production and distribution stages through building a system, which delivers food safety information. This means, IT applications need to be expanded in the agriculture farming automation system.

Direct applications of digital technology include remote sensing (via satellites), geographic information systems, crop and soil health monitoring, and livestock and farm management, among other applications. At the pre-harvest stage, digital technology can recommend crop and input selection and assist in obtaining credit and insurance. At the onfarm stage, there is need for weather advisories and disease- and pest-related assistance; and at the post-harvest stage, realtime data on both domestic and export markets 
are needed. The growth of competitive markets and demand for consistent food quality is making the adoption of such tech based solutions imperative for the Indian farmer. The application of digital technology in agriculture has been instrumental in promoting data generation as well as the advanced analytics that allow farmers to make smart decisions about farming and to benefit from an economical use of inputs and labour.

Digital agriculture can leverage the smart use of data and communication to achieve system optimization. The tools that enable digital agriculture are multiple and varied, and include cross-cutting technologies such as computational decision and analytics tools, the cloud, sensors, robots, and digital communication tools (Table 1).

In addition, field-based activities are enabled by geo-locationing technologies such as Global Positioning Systems (GPS), geographical information systems, yield monitors, precision soil sampling, proximal and remote spectroscopic sensing, unmanned aerial vehicles, auto-steered and guided equipment and variable rate technologies.

Animal-focused technologies include radio frequency identification (RFID chips) and automated (robotic) milking and feeding systems, among others. Controlledenvironment agriculture (greenhouses, indoor farms, etc.) is also increasingly enabled by digital technologies such as sensors and robots (Harold and Woodard, 2017).

\section{Significance of digital transformation in Agriculture}

A digital transformation will help the farmers in multiple ways. It is reflected in the following below diagram. As detailed in the below figure, the following are the key needs from Digital transformation:

\section{Access to finance}

The farmers in India today face acute shortage of money due to the various challenges. Digital transformation helps the farmer in getting access to funds from various sources due to the exposure and awareness they get from being digital.

\section{Forecasts on climate change}

In India (as compared to other advanced countries), the ability to forecast weather changes and in turn the impact that it would have on farming, has been a difficult task. Having the right inputs on potential Climate Change will help the farmer in deciding the right seed to grow and in turn fulfill the demand that is out in the market.

\section{Access to farming equipment and new technology}

In many of the developed countries, Robotics play a bigger role in farming. India is yet to see this advancement and hence there is a crucial need for this transformation.

\section{Inputs for better soil fertility and soil structure}

The farmer in India rarely does an investigation of the fertility of the soil and hence the kind of seed to grow. What has been done in the past generations is what the Indian farmer today develops. There is thus a need to have a more scientific approach to agriculture.

\section{Access to markets}

The farmer, though he does all the hard work today, is not compensated fairly for the work he does. Due to middle-men involved in the buying and selling of the farmer's products, the actual farmer gets a pittance compared to the profits that the middle-men make. There is 
thus a need for a platform which will enable the farmer to sell directly to the buyers (rather than go through middle-men) (Fig. 1).

An emerging ecosystem of digital technologies in Indian agriculture: The rise of start-ups and young entrepreneurial firms

The agriculture sector has attracted large conglomerates, leading IT companies, investors, and young innovators in India; the ecosystem for technology and digital solutions is expanding at an impressive pace. The global market for precision agriculture is expected to grow at an annual growth rate of 13.09 per cent to reach a market size of over US\$6.34 billion by 2022. (BIS research, 2015).The agro-tech start-up ecosystem in India has also been receiving renewed interest from investors, and an estimated 34 ventures received US\$295 million in investments in 2016 in the country - the highest investment amount recorded in India in the past three years (Shaswati, 2017). Among the prominent ventures backed by large conglomerates in India is ITC's e-Choupal, a comprehensive digital knowledge hub for farmers, which has 6,100 installations covering over 35,000 villages and serving over 4 million farmers. (itcportal.com). Launched in 2000, the first-ofits kind initiative not only benefited the farmers doing business through their network, but this model also led to a ripple effect on the public sector-managed food grain management systems that resulted in an upgrade. Mahindra \& Mahindra (M\&M)'s Trringo, a mobile based app enabling farmers to rent tractors, is a unique example of leveraging technology to help farmers use machinery without having to make the large investment (US\$7,500) of buying tractors.(trringo.com). Through Trringo, the farmers are required to pay only for the services they use without locking any money in as capital. This is particularly revolutionary in a country such as India, where agriculture is characterized by smallholders (who operate on less than 2 hectares of land) and who are often resource poor and lack access to formal channels of credit.

\section{Mobile apps}

The growing penetration of mobile phones in rural regions of India is driving the development of several mobile based applications by government departments, entrepreneurs, and the private sector. (tcs.com). The rural subscriber base in India for mobile services has been growing at steady pace, reaching approximately 342 million subscribers in 2012-13, 378 million in 201314 , and 414 million at the end of 2014-15.19 With easier access to mobile phones, farmers can connect with traders and other farmers. Small farmers can also utilize their mobile phones to seek information on input availability or market prices, thereby reducing cost. Other benefits that have been recorded are improved access to information about selecting seed varieties appropriate to a particular farm; and how to identify best cultivation practices, protect from weatherrelated damage, and get a better handle on plant diseases. (Mittal and Mehar, 2013). Some of the examples include Krishi Jagran- a Mobile App for agriculture related News in Hindi, English and Malayalam, duly launched by the Union Minister of Agriculture and Farmers Welfare, Shri Radha Mohan Singh. This app provides information about crop insurance schemes. The Agri Market app has been developed with an aim to keep farmers aware of crop prices and discourage them to go for distress sale. Farmers can get information related to prices of crops in markets within $50 \mathrm{~km}$ of their own device location using the AgriMarket Mobile App.

Kisan Suvidha-launched by Prime Minister Narendra Modi is likely to have many takers 
as India is second largest smart phone market in the world with 87 million mobile internet users in rural areas. The app has a simple interface and provides information on five critical parameters-weather, input dealers, market price, plant protection and expert advisories. An additional tab directly connects the farmer with the Kisan call centre where technical graduates answer their queries. In the last two years, the government has launched nine agricultural apps, including the national agriculture market - eNAM, an electronic trading platform that connects different mandis and markets for farm produce (Anonymous, 2017).

\section{Mobile apps for pest and disease management of crops}

Crop health management is a complex subject. It majorly encompasses problems caused by and solutions for various pestiferous species of insects, viruses, fungi, bacteria, nematodes and weeds, and nutritional deficiencies that decrease crop production and impact farmers welfare. There are numerous species of pests that affect each crop, and not all impact in equal propensities at any given space and time. Pests have always plagued agriculture; the numbers of challenges having multiplied following green revolution. After water, they are perhaps the most worrisome to a farmer, and, post sowing, take a major chunk of his finances. Total crop losses, have been attributed to pests. Modern agriculture has witnessed the rise of many locally unknown pests, or those that once had a "minor pest"e tag on them. Invasive pests, pest resurgence and pest resistance have complicated the issues.

Mobile apps that allow farmers to identify pests and diseases using their mobile phones and provides remedial measures is the latest addition to using modern digital tools to benefit small farmers. A key feature of the mobile app 'Plantix' is automated disease diagnosis. Farmers can upload a photo of their infected crop and the app will provide a diagnosis. Besides giving a diagnosis and steps to mitigate the disease, the app also provides information on preventing the disease in the next cropping season. Farmers are also presented biological treatment options for pest and disease control. The app also features a library of diseases which farmers can refer in case there is no connectivity. Currently, the database has over 60,000 photographs and covers 30 crops in India, 60 crops worldwide and has prescriptions for over 200 crop diseases. Every time a farmer uploads a photograph for diagnosis it will be time marked and geo referenced. Hence, the database also facilitates pest and disease outbreak monitoring and can send early warning messages for specific locations. The app can be downloaded on any Android-based mobile device. Working together with the developers of the app - Progressive Environmental \& Agricultural Technologies (PEAT) - ICRISAT aims to build a database of pest and disease images and content for its six mandate crops (icrisat.org).

\section{Recent developments and challenges in crop protection}

Advances in biotechnology (genetic markers for diseases as an example) should not be overlooked. In the near future, we'll see crops that will be resistant to environmental stresses like drought, and crops that use soil nutrients more efficiently - healthier plants. Field-ready serological tests for disease diagnostics such as lateral flow devices (LFDs) are commonly used as diagnostic tools to aid disease management decision making, to back up diagnoses based on symptoms, and as a triage tool to pre screen plants for specified target diseases, but - Tools developed commercially for use in developed countries are generally too expensive for the same crops in poorer 
countries. DNA-based assays, particularly PCR and real-time/quantitative PCR (qPCR), are being adopted in diagnostic laboratories; ordinary PCR testing for many pathogens is now routine and affordable in the developed world. Digital systems are widely available for distance diagnosis, several free forms of software can be used to map and share the presence of diseases, and these include apps:

Rust Mapper - being tested to map the distribution of wheat stem rust race UG99.

Digital Diagnostic and Identification System (DDIS).

Farmer's Friend aims to provide advice on treating common pests and diseases.

Survillence technologies include use of drones and remote sensing techniques coupled with spectroscopy-based methods - these techniques may be very useful as a rapid preliminary identification of primary infection. Overlaying GIS disease distribution maps with other data could facilitate the possibility of predictive sensing of disease spread and risk could be also used to determine the likely impact of climate change.

Biosensors based on phage display and biophotonics can also instantaneously detect infections. New developments in novel sensors based on the analysis of host responses deliver instantaneous results and can effectively detect early infections directly in the field e-Phyto also holds great potential to assist in plant health efforts by introducing technologies that will facilitate safe trade in plants and plant products. Diseases and deficiencies often go undetected until the crops exhibit clear symptoms - in other words, when it's too late to intervene. This can lead to major yield losses. If farmers can make decisions based on information provided by modern sensor technology and intelligent software, they can run their farms more efficiently. Plants reflect sunlight and hyper spectral cameras capture these reflections in many wavelengths or 'bands'. This allows us to collect very sensitive and detailed information about plants and their physiology. We obtain information about pigment balance in the visible light range, about leaf structure and water balance in the near-infrared range and about constituents and water balance in the shortwave infrared range. Ailing plants have different spectral signatures from healthy ones. Stored information in databases about the efficacy of the crop protection agents for instance, at which stage of growth certain herbicides/fungicides are most effective in controlling weeds. When combined with the field data, this information allows crop protection products to be applied to exactly the square meter that needs them - and nowhere else. As a result, less of the active substance is required. In the summer of 2016, timing and dosage schedule for fungicide for the first time on selected farms throughout Europe (eSAP presentation PDF).

The aim is to use digital technology to monitor large areas of crops so that we can identify plant diseases and stress caused by lack of water or nutrients from a far. By analysing the light spectrum, it is possible to identify pathogens and even the severity of infections. This will enable farmers to respond quickly and use crop protection measures or fertilizer to prevent yield losses.

\section{Other technologies used in agriculture}

Digital technology is a key to increase agriculture productivity by delivering tailored recommendations to farmers based on crop, planting date, variety sown, real time localised observed weather and projected market prices. These recommendations will be based on advanced big data analytics related to downscaled daily observed weather that is now 9 
$\mathrm{km} \times 9 \mathrm{~km}$ but will soon be under $1 \mathrm{~km} \mathrm{x} 1$ $\mathrm{km}$ and effectively field level that feed into crop growth models to estimate yields, harvest date and potential pest and disease outbreaks to optimise pest control measures.

Remote sensing is another big data resource to support the development of derived weather products (radar), improved hydrology and watershed management, soil health, crop coverage and crop health estimates among other application. This is now complimented by Unmanned Aerial Vehicles (UAVs) that can capture multispectral images to assess crop health, damage and yield far more accurately than satellites. Prime Minister Krishi Sinchayee Yojana, national markets and weather indexed insurance, when combined with spatial/temporal data infrastructure, subsidies can be validated (for example, application of fertiliser on a specific field under a targeted fertiliser subsidy programme) and targeted (e.g. digital soil map and crop to be cultivated and rainfall anticipated) to increase farm profitability and manage production and market risks that in turn give farmers confidence to invest in their farms to further increase productivity (Table 1).

Digital Agriculture will also leverage social media platforms to build human capacity. One of the best examples originating from India is Digital Green. It uses participatory videos that have farmers explain best management practices to other farmers. This approach is ten times more cost effective than traditional extension services as farmers trust other farmers because they can better relate to someone like them who are building a livelihood under similar circumstances. Mobile money is the last key intervention that has unlocked tremendous opportunities for rural consumers in Africa and will do the same for India. Paper money is expensive and risky to rural consumers but mobile money is safer, especially for women, and costs less to transfer. Mobile money also allows rural consumers to bypass poor infrastructure to support savings and access credit.

While Digital Agriculture is most advanced in the US, the concepts are scale neutral and are being successfully applied to smallholder farmers around the globe. We need to move with a sense of urgency to apply these new tools to accelerate the pace of agriculture development to not only realize the vision of the Prime Minister of a Digital India but to facilitate the achievement of Sustainable Development Goals before 2030. Digital agriculture will also help achieve the objectives of the National Food Security Act in the most efficient, effective and equitable manner to ensure ALL have access to safe, nutritious and affordable food (Extract of the strategy paper on Digital Agriculture submitted to the Indian Prime Minister's Office upon request).

Technology will continue to play an important role while the dynamics of the agriculture sector changes and produces new challenges. Uptake of technologies at market prices in a sector that has traditionally been heavily subsidized remains challenging, but farmers are prompt to identify what works in their interest and are ready to pay for it. Digital technologies offer the potential to achieve the necessary conditions for scale, with distributed low cost and customized delivery, creating a unique opportunity for private enterprise and innovation to thrive.

A developed agriculture system is based on three key pillars: knowledge, infrastructure, and a robust delivery mechanism. Supporting the research and development ecosystem in agriculture directly contributes to creating knowledge and preparing for the future. To strengthen the supporting framework for growth, it will be important to focus on 
creating new physical markets, improving storage and transport facilities, making better roads, and ensuring a continued electricity and water supply. These system components also facilitate efficient mechanisms for delivery and the monitoring of relevant government schemes and extension services that will accelerate the pace of development. The public policy regime in India has been supporting technology-led agricultural growth and has been increasingly developing new institutions to ease access and affordability of technology adoption among farmers. The challenge before India lies in balancing high growth with inclusive growth; leveraging technology to achieve these twin goals will be a fascinating journey to track.

Table.1 Other technologies used in agriculture in abroad

\begin{tabular}{|c|c|c|}
\hline Production environment & Type of technology & Purpose and benefits \\
\hline \multirow{5}{*}{$\begin{array}{l}\text { Cross-cutting } \\
\text { technologies }\end{array}$} & Computational decision tools & $\begin{array}{l}\text { Use data to develop } \\
\text { recommendations for management } \\
\text { and optimize multitudes of farm } \\
\text { tasks }\end{array}$ \\
\hline & The cloud & $\begin{array}{l}\text { Provide efficient, inexpensive and } \\
\text { centralised data storage to support } \\
\text { farm management }\end{array}$ \\
\hline & Sensors & $\begin{array}{l}\text { Gather information on the } \\
\text { functioning of equipment and farm } \\
\text { resources to support } \\
\text { management decisions }\end{array}$ \\
\hline & Robots & $\begin{array}{l}\text { Implement tasks with efficiency and } \\
\text { minimal human labour }\end{array}$ \\
\hline & $\begin{array}{l}\text { Digital communication tools } \\
\text { (mobile, broadband, } \\
\text { LPWAN) }\end{array}$ & $\begin{array}{l}\text { Allow frequent, real-time } \\
\text { communication between farm } \\
\text { resources, workers, managers, and } \\
\text { computational resources in support } \\
\text { of management }\end{array}$ \\
\hline \multirow[b]{3}{*}{ Field } & Geo-locationing (GPS, RTK) & $\begin{array}{l}\text { Provide precise location of farm } \\
\text { resources (field equipment, animals, } \\
\text { etc.), often combined with } \\
\text { measurements (yield, etc.), or used } \\
\text { to steer equipment to locations }\end{array}$ \\
\hline & $\begin{array}{l}\text { Geographic information } \\
\text { systems }\end{array}$ & $\begin{array}{l}\text { Use computerized mapping to aid } \\
\text { inventory management and to make } \\
\text { geographical } \\
\text { crop input prescriptions (fertilizer, } \\
\text { etc.) }\end{array}$ \\
\hline & Yield monitors & $\begin{array}{c}\text { Employ sensors and GPS on } \\
\text { harvesters to continually measure } \\
\text { harvest rate and make yield maps }\end{array}$ \\
\hline
\end{tabular}




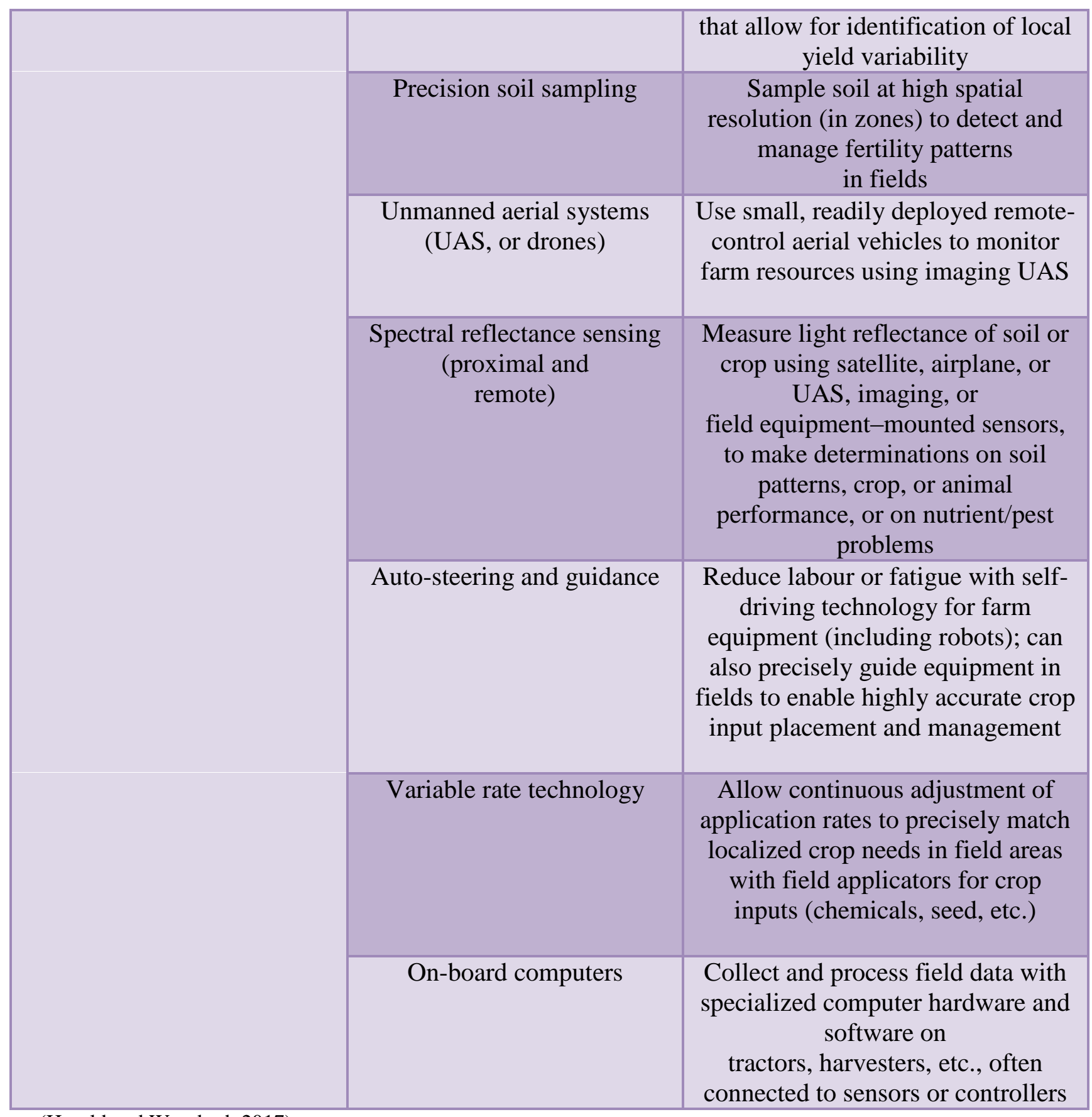

(Harold and Woodard, 2017) 
Fig.1 Advantages of digital transformation in agriculture

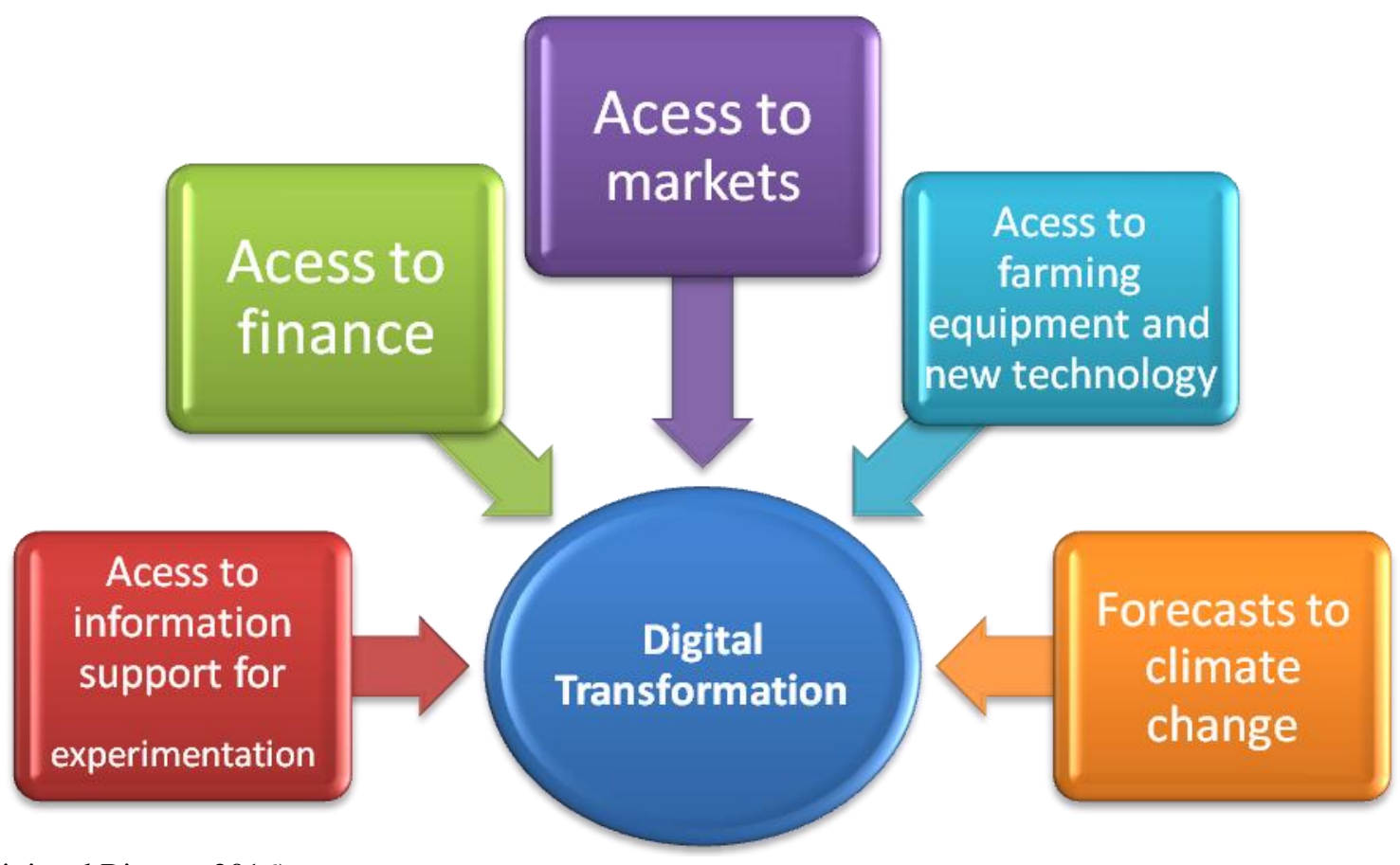

(Shalini and Biswas, 2016)

\section{References}

Anonymous, (2017). Report of Union budget 2017-18. Government of India.

BIS Research. (2015). Global Precision Agriculture Market: Analysis and Forecast, 2016 to 2022.

http://bisresearch.com/industry-report/globalprecision-agriculture-marketanalysisforecast-2015-2022technology-vrasoilmapping-yieldmonitoring-precisionirrigation-otherscomponents-and-systems.Html.eSAP: A PDF presentation available at http://www.mmp.cips.org.in/document s/Workshops/2015/30jul-1aug/eSAPDr._A_Prabhuraj.pdf

Harold, V. and Woodard, J. (2017). Innovation in agriculture and food systems in the digital age. Research in Digital Revolution and New India. 4: 97-103.

http://www.icrisat.org

Information from web resource http://www.itcportal.com/businesses/agribusin ess/agri-commodities-and-ruralservices.aspx.

https://www.tcs.com https://www.trringo.com/about-us.

Mittal, S. and Mehar, M. (2013). Agricultural information networks, information needs and risk management strategies: A Survey of farmers in Indo-Gangetic plains of India. Socioeconomics Working Paper 10. Mexico, D.F.: CIMMYT.

Shalini, R. and Biswas, M. (2016). Will digital technology transform Indian agriculture? Research in Digital Revolution and New India. (ISBN: 978-1-5136-2964-3).

Shashwati, S. (2017). Data harvesting Makes Agri-Tech Startups Hot for Investors.

Economic Times, 23 January.

http://economictimes.indiatimes.com/s mallbiz/startups/data-harvesting-makes 
agritech-startups-hot-forinvestors/articleshow/56726006.cms.

Tang, S., Wu, M., Zhou, X., Zhu, X. (2002). A Conception of digital agriculture, Geo science and Remote Sensing Symposium, IGARSS '02. IEEE International. 5: 3026-2028.
Verma, A.P. (2017). Digitizing and speeding up agriculture development in India. Information available at https://medium.com/fasalapp/digitizing -and-speeding-up-agriculturedevelopment-in-indiacc42b085c471.html.

\section{How to cite this article:}

Snehika Pandia, Reeba Sharma, Nandani Shukla and Roopali Sharma. 2019. Digitalisation in Agriculture: Roads Ahead. Int.J.Curr.Microbiol.App.Sci. 8(12): 1841-1851. doi: https://doi.org/10.20546/ijcmas.2019.812.219 